\title{
Pancreatogastric Fistula with Fish-Mouth Sign
}

\author{
Sara Santos Rita Saraiva Mário Oliveira Diana Carvalho Gonçalo Ramos \\ Centro Hospitalar de Lisboa Central, Lisbon, Portugal
}

Keywords

Fish-mouth sign · IPMN (intraductal papillary mucinous neoplasm) $\cdot$ MPD (main pancreatic duct)

\section{Fístula pancreatogástrica com sinal de boca de peixe}

\section{Palavras Chave}

Sinal de boca de peixe $\cdot$ IPMN $\cdot$ MPD

We report a case of a 72-year-old female referred to a gastroenterology consultation for a finding of main pancreatic duct (MPD) dilation. The patient was a nonsmoker and had a mean daily alcohol intake of $5 \mathrm{~g}$ /day. Her medical history was positive for several episodes of pancreatitis 15 years previously, with biliary lithiasis, for which she underwent laparoscopic cholecystectomy. Subsequently, she had 2 other episodes of pancreatitis, including an infected pancreatic fluid collection (PFC), that underwent conventional endoscopy-guided transgastric drainage at another institution. The patient remained asymptomatic for 14 years.

karger@karger.com www.karger.com/pjg

Karger"

BOPEN ACCESS (c) 2021 Sociedade Portuguesa de Gastrenterologia Published by S. Karger AG, Basel

This is an Open Access article licensed under the Creative Common Attribution-NonCommercial-4.0 International License (CC BY-NC) (http://www.karger.com/Services/OpenAccessLicense), applicable to the online version of the article only. Usage and distribution for commercial purposes requires written permission.
A computed tomography (CT) scan and magnetic resonance cholangiopancreatography (MRCP) revealed irregularity and dilation of the MPD $(8 \mathrm{~mm}$ in the tail and $26 \mathrm{~mm}$ in the body) and a communication with the gastric antrum, with no communication with the cephalic segment or ampulla of Vater. Blood tests were normal, including CEA and CA19.9 levels.

A presumptive diagnosis of disconnected MPD with a gastric fistula due to previous cystic drainage was made, but endoscopic ultrasound (EUS) was performed to exclude a main-duct intraductal papillary mucinous neoplasm (MD-IPMN). Endoscopically, a fistulous orifice 10 $\mathrm{mm}$ wide in the gastric antrum was apparent (Fig. 1), with a gelatinous, high-viscosity content which could not be removed despite vigorous lavage. A gastroscope was used to intubate the fistulous tract, but progression was not possible due to the viscous content. The EUS showed a globally dilated MPD ( $40 \mathrm{~mm}$ in the body) with a loss of interface with the gastric wall in the isthmus, $10 \mathrm{~mm}$ in diameter (Fig. 2). Fine-needle aspiration (FNA) of the MPD with a 19-gauge needle was performed, revealing a very thick mucinous content. Cytologic analysis con-

Correspondence to:

Sara Santos, saramendezleiria@ hotmail.com 


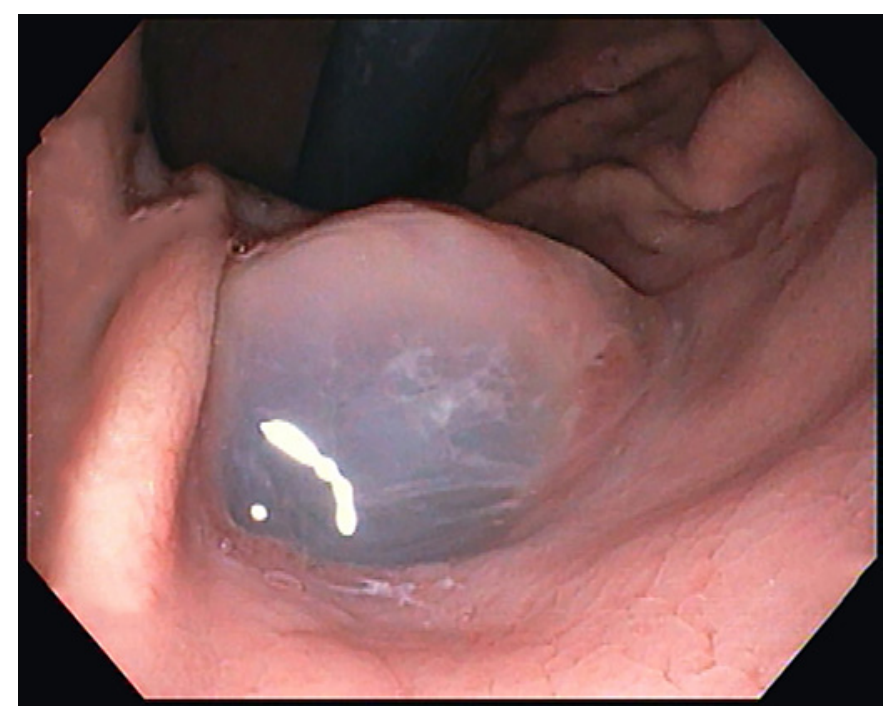

Fig. 1. Endoscopic findings of fistulous orifice with mucinous content.

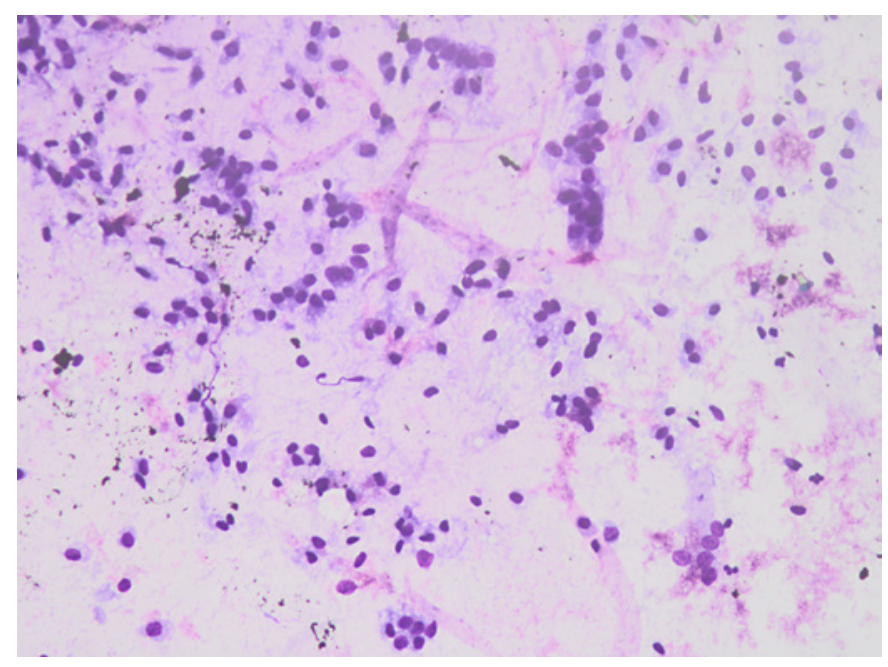

Fig. 3. Cytology.

firmed high-grade IPMN, and the patient was referred to surgery (Fig. 3).

Although IPMN can spontaneously fistulize to adjacent organs $[1,2]$, in this patient, it most likely resulted from a prior drainage procedure. This case underlines the importance of a correct workup prior to endoscopic transmural drainage of PFCs to safely exclude cyst neoplasm, especially in the setting of repeated episodes of pancreatitis. Although the best approach to IPMN fistulization is yet to be defined, a MD-IPMN is a high-risk condition and should be referred to surgery [3].

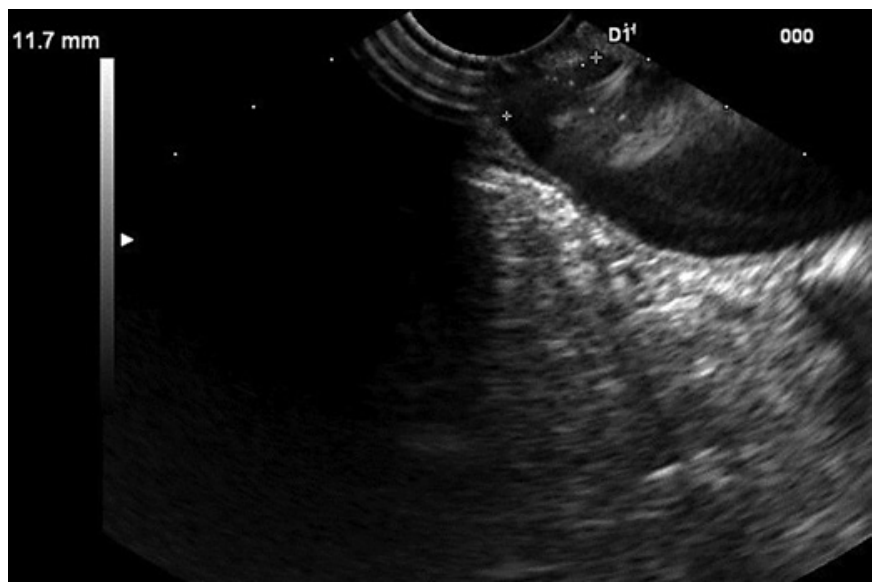

Fig. 2. Endoscopic ultrasound showing fistulous tract to the stomach.

\section{Statement of Ethics}

The patient was provided with a copy of the manuscript and signed a consent form to publish the case.

\section{Conflict of Interest Statement}

There were no conflicts of interest.

\section{Funding Sources}

There was no funding.

\section{Author Contributions}

S.S.: writing of the manuscript and management of the patient. R.S., D.C., and M.O.: patient management. G.R.: patient management and editing of the paper.

\section{References}

1 Ftériche FS, Chebbi F, Bedioui H, Kchir N, Ammous A, Ksantini R, et al. Tumeur intracanalaire papillaire mucineuse du pancréas dégénérée et fistulisée dans l'estomac, le duodénum, et le côlon. Ann Chir. 2006;131(2):118-20.

2 Patel A, Allen A, Kuwahara J, Wadsworth T, Loeffler DM, Xie KL. Intraductal papillary mucinous neoplasm complicated by a gastropancreatic fistula. Radiol Case Rep. 2018;14(3):320-3.

3 Tanaka M, Fernández-Del Castillo C, Kamisawa T, Jang JY, Levy P, Ohtsuka T, et al. Revisions of international consensus Fukuoka guidelines for the management of IPMN of the pancreas. Pancreatology. 2017;17(5):738-53. 